\title{
Translation and Psychometric Evaluation of the Health Orientation Scale in a Greek Speaking Sample (Greece-Cyprus)
}

\author{
Constantinos Togas ${ }^{1}$ a Stavros Parlalis $^{2}$ \\ 1 Social worker-psychologist, Independent researcher, Megalopolis, Arcadia, Greece, 2 Department of Psychology and Social Sciences, Frederick \\ University, Nicosia, Cyprus \\ Keywords: psychometric properties, translation, greek, scale, orientation, health
}

https://doi.org/10.52965/001c.24766

\section{Health Psychology Research}

Vol. 9, Issue 1, 2021

\section{Introduction}

The examination of the impact of personality on physical health outcomes is valuable in health psychology. Health Orientation Scale (HOS) is a 50-item questionnaire developed to evaluate a persons' health orientation.

\begin{abstract}
Aim
To examine the Health Orientation Scale (HOS) psychometric properties in a community Greek-speaking sample in Greece and Cyprus.

\section{Methods}

A cross-sectional study was conducted, which lasted three months. Participants were 358 people between $18-73$ years old (Mage $=34, \mathrm{SD}=9.35)$. There were 86 men $(24.1 \%)$ and 271 women $(75.9 \%)$. The first step included the translation of the HOS. Next, a composite questionnaire was distributed to the participants, including demographic data, Health Orientation Scale, Health Locus of Control Scale, Life Orientation Test-Revised, Body Appreciation Scale (BAS), and State-Trait Anxiety Inventory (STAI). Statistical analysis was performed by SPSS v. 25.
\end{abstract}

\section{Results}

A three-factor structure similar to that found in the original validation was supported. Except for the "External Health Control" subscale $(\alpha=.46)$, the rest nine subscales of the HOS had good/excellent internal consistency, ranging from .76 to .87 . Test-retest reliability of the ten subscales of the HOS was also adequate, ranging from $r=.69$ to .94 . Concerning its construct (convergent and discriminant) validity, many significant correlations were found between the ten subscales of the HOS and Health Locus of Control, Life Orientation Test-Revised, Body Appreciation Scale (BAS), and State-Trait Anxiety Inventory (STAI).

\section{Conclusion}

The HOS is a valuable instrument to health psychologists and could be used for research and clinical purposes to assess people's health orientation.

\section{INTRODUCTION}

Health is defined as "the state of complete physical, mental and social well-being and not merely the absence of disease or infirmity." ${ }^{1}$ Health-related habits (eg. eating a good diet, exercising regularly, having a healthy body weight, brushing one's teeth, refraining from smoking and binge drink- ing, maintaining regular check-ups at a doctor, or receiving preventive vaccines) are crucial for good health. ${ }^{2,3}$ According to Rimal et al., ${ }^{4}$ these health-related habits are components of health orientation.

On the other hand, the importance of psychological processes in the experience of health and illness is being increasingly recognized. More and more evidence is accumulating for the role of behavior in current trends of morbidity

\footnotetext{
a Corresponding author:

Togas Constantinos, 28 Andrea Labrou, Megalopolis, Arcadia, 22200, Greece, Tel.: +30 2791300491. E-mail: togascostas@yahoo.gr
} 
and mortality. 5

People occasionally experience problems and frustrations with the health-related aspects of their lives. Often, the sources of these problems are due to particular personality tendencies and orientations related to their health and physical fitness. ${ }^{6}$ Although the belief that personality is linked to health goes back at least to Greek and Roman times, the scientific study of these links began in earnest only during the last century. ${ }^{7}$

Studies have consistently supported the role of personality variables, such as traits, motives, and goals, as informative for predicting current and future health outcomes. ${ }^{8}$ The causal relation between personality and health may run in both directions; personality influences health, and health influences personality. ${ }^{7}$ It is well documented that psychological factors (such as personality) can affect health directly (such as stress causing the release of several hormones which damage the body over time) and indirectly via a person's own behavior choices, which can harm or protect health (such as smoking or taking exercise).

In this sense, personality is an essential aspect of people's physical well-being and health. However, not all aspects of personality tend to be associated in a negative direction with physical health. More conscientious people have better health and live longer lives than less conscientious people. ${ }^{7}$ Extraversion has been related to better health and well-being and has also been linked to health behaviors, but in a diverse way. ${ }^{9}$ Agreeableness is related to better health behaviors, while lower levels of this trait have been associated with increased mortality risk. ${ }^{10,11}$ On the other contrary, high levels of neuroticism have been positively correlated with poorer physical functioning, worse illness outcomes, greater alcohol consumption as well as increased cigarette smoking. ${ }^{12,13}$

Partner personality characteristics, such as agreeableness, conscientiousness, and emotional stability, are also important determinants of health. ${ }^{14}$ Several other studies and theories link psychological factors and personality with health outcomes. ${ }^{15-20}$

However, there are still quite many unknown and unclear indications as to the interplay of psychological and physical factors in health and illness. ${ }^{21}$ In this context, health orientation seems to be a significant variable. Health orientation is an individual-differences concept defined as an individual's motivation to engage in healthy attitudes, beliefs, and behaviors. ${ }^{22}$ As suggested by Dutta-Bergman, ${ }^{23}$ health-oriented individuals are more likely to have a positive orientation toward various preventative behaviors and engage in healthy activities.

There is also extensive interest in understanding the relationship between the personality variable of health locus of control and various health attitudes, behaviors, and situations.

Health locus of control examines the degree to which individuals believe that their health is controlled by internal (i.e., direct result of one's actions) or external (i.e., medical professionals, fate, luck, etc.) factors and is associated with people's orientations toward their health. ${ }^{24}$ In recent decades, a great deal of research has linked internal locus of control to positive health beliefs and behaviors.

Health anxiety is also a common and distressing prob- lem, affecting most people at some point in their lives and becoming clinically significant for up to $5 \%$ of the general population at any one time. ${ }^{25}$ Health anxious individuals tend to treat their symptoms as authentically threatening and accept their thoughts about the illness as relevant. They often experience urges to seek medical consultation to get reassured about good health or cure the presumed disease. ${ }^{26}$

Another relative variable, health consciousness, refers to the extent to which an individual tends to undertake health actions and is divided into four dimensions: greater concerns to health, caring about health, engaging in searching for health information, and valuing healthy conditions. ${ }^{27}$ Health consciousness predicts various health attitudes and behaviors and is closely related to how he or she seeks and responds to health information. ${ }^{28}$

All the above approaches and findings are espoused in the biopsychosocial model of health. They suggest that personality and psychological tendencies need to be considered more extensively when investigating the variables that promote physical health and fitness.

Following these researches, there is a need to use several measurement instruments that focuses more comprehensively and directly on the linkage of personality variables with physical health outcomes. The Health Orientation Scale (HOS), developed by Snell et al., ${ }^{6}$ is such a questionnaire. It was developed from a need for an instrument that focuses more comprehensively and directly on measuring personality variables related to physical health. The personality tendencies measured by the Health Orientation Scale are those dealing with the following concepts: (1) personal health consciousness, (2) health image concern, (3) health anxiety, (4) health esteem-confidence, (5) motivation to avoid unhealthiness, (6) motivation for healthiness, (7) internal health control, (8) external health control, (9) health expectations, and (10) health status.

Health Orientation Scale has been used in several studies examining alcohol consumption, ${ }^{29}$ genetic self-knowledge, ${ }^{30}$ and in several samples, like women, ${ }^{31}$ stoma patients $^{32}$ and African American men, ${ }^{33}$ etc.

This study aimed to translate and culturally adapt the Health Orientation for the Greek and Cyprus populations (the Greek language is spoken in Greece and Cyprus). More specifically, the objectives were to examine the factor structure of the questionnaire and its psychometric properties (internal consistency, test-retest reliability, construct validity). To the best of the authors' knowledge, there is a shortage of relevant questionnaires in the Greek language. Consequently, the Greek version of the Health Orientation Scale overcomes this shortage and can be administered for clinical and research purposes by health and clinical psychologists.

\section{METHOD}

\section{TRANSLATION OF THE QUESTIONNAIRE}

The translation strategy was based on minimal translation criteria developed by the Scientific Advisory Committee of the Medical Outcomes Trust (2002) and on a set of guidelines by the International Test Commission. ${ }^{34}$ 
The translation was performed using a multiple forward and backward translation protocol. Two independent bilingual professionals translated the questionnaire into Greek (forward translation). The mother language of all translators was Greek, and their level of English was advanced. Then followed the reconciliation report (which aligns the two translations) from a bilingual professional who has Greek as the mother language for the final agreed version to be extracted. After that, the reconciliated Greek version of the questionnaire was retranslated into English by two native English speakers, who were blinded to the original version (backward translation).

The last step of the translation procedure was the pretesting of the translated instrument. Fifteen people were randomly assigned to participate in the cognitive debriefing process and confirm that the scale could be read and understood by the persons of the sample. After completing the questionnaire, they were asked to interpret the questions, their general impression on the clarity of the items, and give translation alternatives. Moreover, they were asked about the comprehensiveness of the instructions and their ability to complete them on their own. Their comments and suggestions were used to prepare the instructions and ensure that participants had no difficulties reading the items. The average time for completing the questionnaire was eight minutes. There was an attempt to maintain all the key features of the questionnaire during the translation in the Greek language. Still, all the necessary changes to adjust it to the Greek culture were made.

\section{DESIGN}

A cross-sectional study with a snowball recruitment procedure was conducted. The duration of the study was three months. The questionnaires were administered to Greece and Cyprus, and the majority of them were distributed electronically.

The participants were selected based on the following eligibility criteria:

1. male-female persons with sufficient ability to understand and respond to the questionnaire.

2. age $>18$ years

3. residents of Greece or Cyprus

4. ability to speak-understand the Greek language

5. persons wishing to participate voluntarily in the research.

Persons who did not wish to participate voluntarily in the research and those who could not respond to the questions were excluded from the study.

The questionnaire consisted of two parts: the first part included sociodemographic data. The second part included the following questionnaires: 1) Health Orientation Scale (HOS), 2) Health Locus of Control, 3) Life Orientation TestRevised, 4) Body Appreciation Scale (BAS), and 5) StateTrait Anxiety Inventory (STAI). These questionnaires were used to examine the construct (convergent and discriminant validity) of the Health Orientation Scale and have been translated and culturally adapted in the Greek population by several scholars.

The participants were informed in detail about the pur- pose of the study and were given assurances of anonymity and confidentiality of the information. They were also assured that the collected data would be used only for the study. All participants took part voluntarily, without taking any remuneration.

A new study examined the test-retest reliability of the Health Orientation Scale scores. The participants completed the HOS three weeks later under the same conditions as the first study. Test-retest reliability was not examined in the initial validation of the HOS

\section{PARTICIPANTS}

The sample comprised 358 persons of the Greek and Cypriot general population. The mean age of the participants was 34 years (Mage $=34.00, \mathrm{SD}=9.35, \mathrm{Min}=18, \mathrm{Max}=73$, Range $=55$ ). The rest demographic characteristics of the sample are presented in Table 1.

The sample used to examine the test-retest reliability consisted of 35 persons randomly selected, aged between $31-47$ (Mean age $=35.8, \mathrm{SD}=6.14)$. Fourteen of them were men (40\%), and twenty-one (60\%) were women.

\section{MEASURES}

\section{DEMOGRAPHICS}

Patients reported their gender, age group $(<25$ years, $26-39$ years, $>40$ years), marital status, educational level, and occupation.

\section{HEALTH ORIENTATION SCALE (HOS)}

It is an objective self-report questionnaire that evaluates men's and women's personality tendencies towards physical health or health orientation. It is composed of fifty items divided into ten health-oriented subscales, each containing five items, and measures several health-related personality features:

1) personal health consciousness, defined as the tendency to be highly aware of and think about one's physical healthfitness, eg. "I am very aware of how healthy my body feels."

2) health image concern, defined as the tendency to be highly aware of the external, observable impression that one's physical health makes on others, eg. "I sometimes wonder what others think of my physical health."

3) health anxiety, defined as the tendency to be anxious and nervous about one's physical health-fitness, eg. "I feel anxious when I think about my health.”

4) health esteem-confidence, defined as a generalized tendency to positively evaluate and feel confident about one's physical health, eg. "I feel confident about the status of my health."

5) motivation to avoid unhealthiness, defined as the motivation and desire to avoid being in a state of unhealthiness, eg. "I am motivated to keep myself from becoming physically unhealthy."

6) motivation for healthiness, defined as the motivational tendency and desire to keep oneself in excellent physical health, e.g., "I'm very motivated to be physically healthy."

7) internal health control, defined as the tendency to believe that one's physical health and fitness is a direct func- 


\begin{tabular}{|c|c|c|}
\hline & Frequency & Percentage (\%) \\
\hline \multicolumn{3}{|l|}{ Gender } \\
\hline Men & 86 & $24.1 \%$ \\
\hline Women & 271 & $75.9 \%$ \\
\hline \multicolumn{3}{|l|}{ Age group } \\
\hline$\leq 25$ years & 73 & $20.4 \%$ \\
\hline $26-39$ years & 199 & $55.7 \%$ \\
\hline$>40$ years & 85 & $23.8 \%$ \\
\hline \multicolumn{3}{|l|}{ Marital status } \\
\hline Single & 161 & $45.1 \%$ \\
\hline Married/partnered & 179 & $50.1 \%$ \\
\hline Divorced & 15 & $4.2 \%$ \\
\hline Widow/widower & 2 & $0.6 \%$ \\
\hline \multicolumn{3}{|l|}{ Level of education } \\
\hline Secondary school & 1 & $0.3 \%$ \\
\hline Lyceum & 18 & $5.0 \%$ \\
\hline Higher education (students) & 44 & $12.3 \%$ \\
\hline Higher education (graduates) & 137 & $38.4 \%$ \\
\hline Ma/M.Sc. holder & 128 & $35.9 \%$ \\
\hline Ph.D. holder & 29 & $8.1 \%$ \\
\hline \multicolumn{3}{|l|}{ Occupation } \\
\hline Student & 38 & $10.7 \%$ \\
\hline Unemployed & 41 & $11.55 \%$ \\
\hline Civil Servant & 77 & $21.69 \%$ \\
\hline Private employee & 155 & $43.66 \%$ \\
\hline Housewife & 7 & $1.97 \%$ \\
\hline Freelancer & 34 & $9.58 \%$ \\
\hline Pensioner & 3 & $0.85 \%$ \\
\hline
\end{tabular}

tion of one's behaviors and actions, eg. "My health is something that I alone am responsible for.” People with higher internal health control scores believe that they have control over their physical health status.

8) external health control, defined as the tendency to believe that one's health status is determined by uncontrollable factors external to oneself, e.g., "Being in good physical health is just a matter of luck." Those with higher scores in the external health control subscale believe that such factors influence their physical health as luck and chance.

9) health expectations, defined as the tendency to expect that one's health will be excellent and positive in the future, eg. "I expect that my health will be excellent in the future."

10) health status, defined as the tendency to regard oneself as being currently well-exercised and in good physical shape, eg. "I am in good physical health." 6

Concerning the scoring, respondents are asked to indicate to what extent each item is characteristic of them and rate it in a 5 -point Likert scale $(1=$ Not at all characteristic of me, 2 = Slightly characteristic of me, $3=$ Somewhat characteristic of me, $4=$ Moderately characteristic of me, $5=$ Very characteristic of me). Items $14,38,39,40,48,49,50$ are reversed scored. The total score for each subscale is the sum of the corresponding five items and ranges from 5 to 25 . The greater the score, the greater the corresponding tendency of the respondent.

Concerning its psychometric properties, reliability analysis provided evidence of internal consistency for the subscales on the Health Orientation Scale (HOS). The internal consistency was evaluated using Cronbach alpha coefficient: subscales reported a value included within 0.69-0.92.

\section{HEALTH LOCUS OF CONTROL}

It includes 18 belief statements that assess a person's beliefs regarding whether his or her health status is determined by the actions of individuals (as opposed to fate, luck, or chance) and, if so, whether the locus of that control is "internal" (i.e., residing in the person's actions) or "external" (i.e., dependent on the actions of other people). The items are subdivided into three 6-item subscales: (1) Internal HLC (items 1,6,8,12,13,17), which evaluates the level of control attributed to the individual, e.g., "If I get sick, it is my behavior that determines how soon I get well again" (2) Powerful Others HLC (items 3,5,7,10,14,18), which evaluates the level of control attributed to other persons (such 
as health providers, social leaders, etc.), e.g., "Having regular contact with my physician is the best way for me to avoid illness"; and (3) Chance HLC (items 2,4,9,11,15,16), which evaluates the level of control attributed to luck, fate or chance, e.g., "No matter what I do, I 'm likely to get sick." Each item is rated on a 6-point Likert-type scale, ranging from strongly disagree (1) to strongly agree (6), with higher scores indicate a stronger tendency towards that type of control. The alpha reliabilities of the six-item subscales range from .65 to .75 , and the test-retest reliabilities are in the range of $.70-30 .^{24}$ In the present study, the Greek translation of the questionnaire was used, and Cronbach's $\alpha$ was .68 for the Internal HLC subscale, .71 for Powerful Others HLC subscale, and .76 for Chance HLC subscale.

\section{LIFE ORIENTATION TEST-REVISED}

The life orientation test-revised (LOT-R) consists of 10 items, and it is a brief measure for assessing dispositional optimism. In psychology, optimism is viewed as a general way of thinking that can be beneficial to health outcomes. It has been used in a good deal of research on the behavioral, affective, and health consequences of the Optimism/ Pessimism dimension. Three items measure optimism (e.g., "In uncertain times, I usually expect the best"), three things measure pessimism (e.g., "If something can go wrong for me, it will”), and four items $(2,5,6,8)$ serve as fillers. Each item is scored $0-4$, while items $3,7,9$ are reversed scored. The possible range of total scores is $0-24$, and high values imply optimism. ${ }^{35}$ According to another scoring system, values 19-24 indicate high optimism, values 14-18 indicate moderate optimism, and values $0-13$ indicate low optimism. ${ }^{36}$ In this study, the former scoring system was used.

The scale has an acceptable internal consistency and test-retest reliability. ${ }^{37}$ Its Greek version has a two-factor structure representing the constructs of optimism and pessimism, good internal consistency and convergent validity, and stability over three months. ${ }^{38}$ In the present study, Cronbach's $\alpha$ was .67 for both optimism and pessimism subscale.

\section{BODY APPRECIATION SCALE (BAS)}

It consists of 13 items and evaluates the positive body image (e.g. "I feel good about my body"). It measures four aspects: favorable opinions of one's own body, acceptance of the body despite its imperfections, respect for the body, particularly to its needs, and protection of the body, including rejection of unrealistic ideals. Item 12 is gender-specific, and there is a different question for both men and women. The questionnaire items are rated on a 5-point scale ( $1=$ Never, $5=$ Always $)$ and are averaged to obtain a total score (item 12 is reversed scored in the Greek version). Higher scores reflect greater body appreciation. Psychometric properties (reliability, validity, etc.) of BAS are adequate, and its factor structure comprises a single dimension. ${ }^{39}$ Its Greek version presents adequate construct validity, internal consistency, and test-retest reliability. ${ }^{40}$ In the present study, Cronbach's $\alpha$ was .89 for the total score of the scale.

\section{STATE-TRAIT ANXIETY INVENTORY (STAI)}

It consists of 40 items, divided into two subscales: a) state anxiety (emotional state of the subject at the time of the survey, e.g., "I feel calm”) and b) trait anxiety (emotional state of the person in general, e.g., "I worry too much over something that really does not matter"). The questionnaire items are rated on a 4 -point scale $(1=$ Not at all, $4=$ Very much). Items $1,2,5,8,10,11,15,16,20,21,26,27,33,36,39$ are reversed scored. Apart from the score in each subscale, there is a general index by adding all of the items. Considerable evidence attests to its construct and concurrent validity, internal consistency, and test-retest reliability. ${ }^{41,42}$

The Greek version of the questionnaire has demonstrated adequate construct validity, internal consistency, and test-retest reliability. ${ }^{43}$ In the present study, Cronbach's $\alpha$ was .92 for the total items and .91 for the "State" and .92 for the "Trait" subscales.

\section{DATA ANALYSIS}

Data analysis was conducted by using SPSS v.25, and the statistical significance was set to $5 \%$. Results were obtained using descriptive statistics, T-test, ANOVA, and Pearson's correlation. Moreover, Exploratory Factor Analysis (EFA) was carried out to examine the factor structure of the Health Orientation Scale. The Bartlett's test of sphericity and the Kaiser-Meyer-Olkin index were used to determine if the HOS items had an adequate variance for factor analysis. In EFA, principal component analysis (PCA) with a varimax rotation was utilized to assess the internal structure of the measure. Exploratory Factor Analysis (EFA) was performed in subscales and not in items, based on the analysis performed in the original validation. Varimax rotation was selected because it was expected that the factors were not strongly intercorrelated. The number of factors was determined according to those with eigenvalues $>1$ and by examining the scree plot. Item-component correlations of 0.4 and above were retained.

The internal consistency reliability of the instrument was assessed by using Cronbach's alpha coefficient. Alpha coefficient values of 0.70 or higher were deemed to indicate good reliability.

Construct (convergent and discriminant) validity were assessed by computing the Pearson's correlation between the HOS and the rest questionnaires (Health Locus of Control, Life Orientation Test-Revised, Body Appreciation Scale, State-Trait Anxiety Inventory).

Test-retest reliability was examined using paired samples t-test, Interclass Correlation Coefficients, and Pearson's correlation in the test-retest sample (first and second administration).

\section{RESULTS}

\section{FACTOR ANALYSIS RESULTS}

A principal component factor analysis with varimax rotation was conducted on the ten subscales on the Health Orientation Scale. Bartlett's test of sphericity $\left(x^{2}=1344.86\right.$, $p<.001)$ and the Kaiser-Meyer-Olkin index (.804) confirmed that the HOS items had an adequate variance for factor 
Table 2. Factor Analysis of the Subscales on the Health Orientation Scale (HOS)

\begin{tabular}{|c|c|c|c|}
\hline \multirow{2}{*}{ Subscales on the Health Orientation Scale (HOS) } & \multicolumn{3}{|c|}{ Factor Solutions } \\
\hline & 1 & II & III \\
\hline \multicolumn{4}{|l|}{ FACTOR ANALYSIS RESULTS } \\
\hline Eigenvalue & 3.62 & 1.86 & 1.43 \\
\hline Percent of Variance & 36.21 & 18.57 & 14.32 \\
\hline \multicolumn{4}{|l|}{ HEALTH ORIENTATION SCALE } \\
\hline Personal Health Consciousness & .625 & & \\
\hline Health Esteem-Confidence & .832 & & \\
\hline Motivation to Avoid Unhealthiness & .814 & & \\
\hline Motivation for Healthiness & .875 & & \\
\hline Health Expectations & .662 & & \\
\hline Health Status & .701 & & \\
\hline Health Image Concern & & .778 & \\
\hline Health Anxiety & & .860 & \\
\hline Internal Health Control & & & .709 \\
\hline External Health Control & & & -869 \\
\hline
\end{tabular}

Note. Extraction method= Principal component analysis with varimax rotation

Table 3. Descriptive Statistics for the Subscales of The Health Orientation Scale

\begin{tabular}{lccc}
\hline & N & Mean & Std. Deviation \\
Personal Health Consciousness & 319 & 19.26 & 3.49 \\
Health Image Concern & 319 & 10.67 & 4.74 \\
Health Anxiety & 319 & 14.90 & 3.93 \\
Health Esteem-Confidence & 319 & 16.23 & 4.52 \\
Motivation to Avoid Unhealthiness & 319 & 17.62 & 4.42 \\
Motivation for Healthiness & 319 & 17.72 & 3.78 \\
Internal Health Control & 319 & 20.60 & 3.31 \\
External Health Control & 319 & 11.21 & 4.21 \\
Health Expectations & 319 & 16.10 & 4.31 \\
Health Status & 319 & 14.38 & \\
\hline
\end{tabular}

analysis.

Analysis revealed three factors with eigenvalues $>1$, which explained $69.1 \%$ of the variance. The factor loadings and results are presented in Table 2. As an inspection of this table reveals, Personal Health Consciousness, Health Esteem-Confidence, Motivation to Avoid Unhealthiness, Motivation for Healthiness, Health Expectations, and Health Status subscales all had high loadings factor (eigenvalue $=3.62$; percent of variance $=36.21$ ). Factor II consisted of the subscales dealing with the Health Expectations and Health Status subscales (eigenvalue $=1.86$; percent of variance $=$ 18.57). The third and final factor consisted of the subscales dealing with Internal Health Control and External Health Control (eigenvalue $=1.43$; percent of variance $=14.31$ ) .

This factor structure of the HOS was also supported by the scree plot (figure 1). This model is entirely similar to that found in the original validation of the Health Orienta- tion Scale. ${ }^{6}$. As it is reported in the initial validation, “....although these three clusters were found, it is important that researchers not arrive at the mistaken conclusion that the HOS subscales which loaded on each factor are assessing identical tendencies. Later results show, for example, that while some of these subscales relate to particular healthseeking behaviors, others do not". Moreover, "the loadings indicate that people who consider themselves healthy right now and who expect to continue feeling healthy in the future are the most motivated for good health, have higher health-esteem, and have higher levels of personal health consciousness." 6

Descriptive statistics for the ten subscales of the HOS are presented in table 3 . The highest mean score is recorded in the subscale Internal Health Control (20.60) and the lowest in the subscale Health Image Concern (10.67). 
Table 4. Reliability Coefficients for the Health Orientation Scale

\begin{tabular}{lc}
\multicolumn{1}{c}{ Subscales on the Health Orientation Scale (HOS) } & Cronbach's Alpha \\
\hline 1. Personal Health Consciousness & .76 \\
2. Health Image Concern & .87 \\
3. Health Anxiety & .86 \\
4. Health Esteem-Confidence & .81 \\
5. Motivation to Avoid Unhealthiness & .76 \\
6. Motivation for Healthiness & .84 \\
7. Internal Health Control & .84 \\
8. External Health Control & .46 \\
9. Health Expectations & .80 \\
10. Health Status & .79 \\
\hline
\end{tabular}

Note. Each subscale consisted of 5 items. Range for all subscales $=0-20$.

Table 5. Correlations Among the Subscales on the Health Orientation Scale

\begin{tabular}{|c|c|c|c|c|c|c|c|c|c|c|}
\hline $\begin{array}{c}\text { Subscales on the } \\
\text { Health } \\
\text { Orientation Scale } \\
\text { (HOS) }\end{array}$ & $\mathrm{PHC}$ & HIC & $\mathrm{HA}$ & HEC & MAU & MFH & $\mathrm{IHC}$ & $\mathrm{EHC}$ & $\mathrm{HE}$ & $\mathrm{HS}$ \\
\hline $\mathrm{PHC}$ & 1.00 & & & & & & & & & \\
\hline HIC & $.12^{*}$ & 1.00 & & & & & & & & \\
\hline $\mathrm{HA}$ & $.14^{* *}$ & $.50^{* *}$ & 1.00 & & & & & & & \\
\hline HEC & $.49^{* *}$ & -.09 & $.21^{* *}$ & 1.00 & & & & & & \\
\hline MAU & $.58^{* *}$ & .08 & .05 & $.58^{* *}$ & 1.00 & & & & & \\
\hline MFH & $.58^{* *}$ & .06 & .06 & $.65^{* *}$ & $.79^{* *}$ & 1.00 & & & & \\
\hline $\mathrm{IHC}$ & $.41^{* *}$ & $.15^{* *}$ & .09 & $.38^{* *}$ & $.40^{* *}$ & $.39^{* *}$ & 1.00 & & & \\
\hline $\mathrm{EHC}$ & $-.12^{*}$ & $.18^{* *}$ & $.24^{* *}$ & $-17^{* *}$ & $-.17^{* *}$ & $-.13^{*}$ & $-.37^{* *}$ & 1.00 & & \\
\hline $\mathrm{HE}$ & $.32^{* *}$ & .04 & $-.23^{* *}$ & $.53^{* *}$ & $.41^{* *}$ & $.49^{* *}$ & $.41^{* *}$ & $-.23^{* *}$ & 1.00 & \\
\hline $\mathrm{HS}$ & $.25^{* *}$ & $-.14^{* *}$ & $-.30^{* *}$ & $.60^{* *}$ & $.42^{* *}$ & $.51^{* *}$ & $.25^{* *}$ & $-.20^{* *}$ & $.51^{* *}$ & 1.00 \\
\hline
\end{tabular}

Note. $\mathrm{N}=358 . \mathrm{PHC}=$ Personal Health Consciousness; HIC = Health Image Concern; HA = Health Anxiety; HEC = Health Esteem-Confidence; MAU = Motivation to Avoid Unhealthiness; MFH = Motivation for Healthiness; IHC = Internal Health Control; EHC = External Health Control; HE = Health Expectations; and HS = Health Status.

*. Correlation is significant at the 0.05 level (2-tailed).

**. Correlation is significant at the 0.01 level (2-tailed).

\section{INTERNAL CONSISTENCY RELIABILITY ANALYSES}

The internal consistency of the ten subscales on the Health Orientation Scale was determined by calculating Cronbach's alpha coefficients. Their value ranged from a low .46 to a high of .87 (Table 4). There was a problem with the subscale External Health Control. Cronbach's $\alpha$ was low (.46) in this subscale, but if item 38 ("Being in excellent physical shape has little or nothing to do with luck") was deleted, the value of Cronbach's $\alpha$ raised to an acceptable value (.65). We chose not to delete item 38 to retain the original 50-items structure of the scale. However, since item 38 proved to be psychometrically unsound, researchers may want to consider eliminating it from the total score of the subscale External Health Control.

In summary, nine out of the ten subscales on the Health
Orientation Scale had good/excellent internal consistency reliability, thereby justifying their use in the following analyses.

\section{CORRELATIONS AMONG THE SUBSCALES}

The correlations among the subscales on the Health Orientation Scale are presented in Table 5. The strongest correlation was recorded between the two health motivational subscales, with both motivational tendencies contributing to the personal health consciousness and health esteemconfidence. There was also a strong positive correlation between Health Esteem-Confidence and Motivation for Healthiness with Health Expectations and Health Status. In addition, a strong positive correlation was found between Health Anxiety and health image concerns. 
Table 6. Construct Validity Correlations Between the Health Orientation Scale and the Rest Questionnaires

\begin{tabular}{|c|c|c|c|c|c|c|c|c|c|c|}
\hline & \multicolumn{10}{|c|}{ Subscales on the Health Orientation Scale } \\
\hline & PHC & HIC & HA & HEC & MAU & $\mathrm{MFH}$ & IHC & EHC & HE & HS \\
\hline $\begin{array}{l}\text { Internal } \\
\text { Health Locus } \\
\text { of Control }\end{array}$ & $.193^{* *}$ & $.121^{*}$ & .021 & $.159^{* *}$ & $.186^{* *}$ & $.196^{* *}$ & $.447^{* *}$ & $-.239^{* *}$ & $.257^{* *}$ & .057 \\
\hline $\begin{array}{l}\text { Powerful } \\
\text { Others } \\
\text { Health Locus } \\
\text { of Control }\end{array}$ & .043 & $.120^{*}$ & $.229^{* *}$ & .009 & .077 & .090 & -.013 & .092 & -.018 & -.073 \\
\hline $\begin{array}{l}\text { Chance } \\
\text { Health Locus } \\
\text { of Control }\end{array}$ & -.064 & $.122^{*}$ & $.151^{* *}$ & -.074 & -.079 & -.042 & $-.247^{* *}$ & $.325^{* *}$ & $-.144^{* *}$ & -.081 \\
\hline $\begin{array}{l}\text { Life } \\
\text { Orientation } \\
\text { Test-Revised }\end{array}$ & $.256^{* *}$ & $-.161^{* *}$ & $-.262^{* *}$ & $.370^{* *}$ & $.314^{* *}$ & $.322^{* *}$ & $.180^{* *}$ & $-.241^{* *}$ & $.419^{* *}$ & $.280^{* *}$ \\
\hline $\begin{array}{l}\text { Body } \\
\text { Appreciation } \\
\text { Scale }\end{array}$ & $.294^{* *}$ & $-.325^{* *}$ & $-.384^{* *}$ & $.586^{* *}$ & $.378^{* *}$ & $.446^{* *}$ & $.166^{* *}$ & $-.179^{* *}$ & $.366^{* *}$ & $.540^{* *}$ \\
\hline $\begin{array}{l}\text { STAI (total } \\
\text { score) }\end{array}$ & $-.185^{* *}$ & $.289^{* *}$ & $.462^{* *}$ & $-.391^{* *}$ & $-.240^{* *}$ & $-.227^{* *}$ & $-.161^{* *}$ & $.375^{* *}$ & $-.362^{* *}$ & $-.330^{* *}$ \\
\hline STAI- State & $-.185^{* *}$ & $.216^{* *}$ & $.438^{* *}$ & $-.359^{* *}$ &.$- .04^{* *}$ & $-.206^{* *}$ & $-.145^{* *}$ & $.334^{* *}$ & $-.339^{* *}$ & $-.305^{* *}$ \\
\hline STAI-Trait & $-.169^{* *}$ & $.347^{* *}$ & $.448^{* *}$ & $-.393^{* *}$ & $-.244^{* *}$ & $-.233^{* *}$ & $-.135^{*}$ & $.324^{* *}$ & $-.314^{* *}$ & $-.308^{* *}$ \\
\hline
\end{tabular}

Note.

*. Correlation is significant at the 0.05 level (2-tailed).

**. Correlation is significant at the 0.01 level (2-tailed).

PHC=Personal Health Consciousness; HIC=Health Image Concern; HA=Health Anxiety; HEC=Health Esteem-Confidence; MAU=Motivation to Avoid Unhealthiness; MFH=Motivation for Healthiness; IHC=Internal Health Control; EHC=External Health Control; HE=Health Expectations; and HS=Health Status.

\section{CONSTRUCT VALIDITY OF THE HEALTH ORIENTATION}

\section{SCALE}

The validity of the Health Orientation Scale was examined by computing correlations between the subscales on the HOS and Health Locus of Control Scale, Life Orientation Test-Revised, Body Appreciation Scale, and State-Trait Anxiety Inventory (STAI) (table 6). An inspection of this table indicates that there are many significant correlations. The strongest correlations were the following:

- Health Anxiety (HA) was negatively associated with body appreciation and positively with state and trait anxiety and total score of STAI.

- Health Esteem-Confidence (HEC) was positively correlated with body appreciation and life orientation and negatively with state and trait anxiety and total score of STAI.

- Motivation to Avoid Unhealthiness (MAU) and Health Status (HS) were positively correlated with body appreciation and life orientation.

- Internal Health Control (IHC) was positively correlated with Internal Health Locus of Control

- External Health Control (EHC) was positively correlated with Chance Health Locus of Control, state and trait anxiety, and total score of STAI.

- Health Expectations (HE) was positively correlated with Life Orientation and body appreciation and negatively with state and trait anxiety and total score of STAI.

- Health Status (HS) was positively correlated with

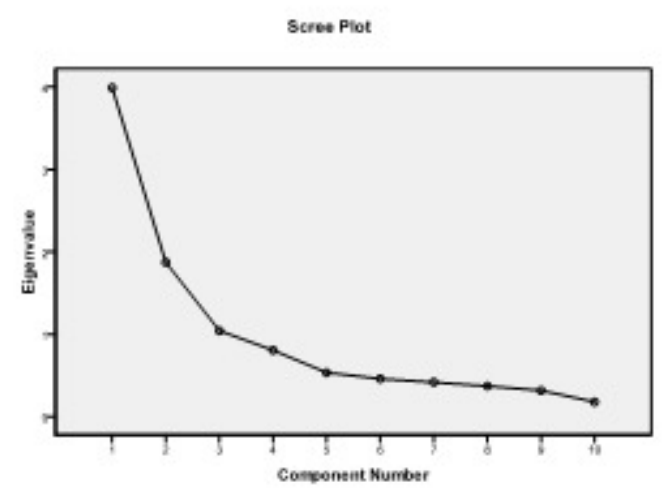

Figure 1. Scree plot

body appreciation and negatively with state and trait anxiety and total score of STAI.

These results suggest that the Greek version of the Health Orientation Scale has adequate construct (convergent and discriminant) validity.

\section{TEST-RETEST RELIABILITY}

A significant positive correlation was found between the first and second administration scores for all the subscales of HOS (table 7). Interclass Correlation Coefficients were also adequate-excellent for all the subscales of HOS 
Table 7. Correlations in the Test-Retest Sample (First and Second Administration)

\begin{tabular}{llr}
\multicolumn{1}{c}{ Subscales on the Health Orientation Scale (HOS) } & \multicolumn{1}{c}{$.825^{* *}$} \\
\hline 1. Personal Health Consciousness & $.938^{* *}$ \\
2. Health Image Concern & $.795^{* *}$ \\
3. Health Anxiety & $.689^{* *}$ \\
4. Health Esteem-Confidence & $.873^{* *}$ \\
5. Motivation to Avoid Unhealthiness & $.832^{* *}$ \\
6. Motivation for Healthiness & $.701^{* *}$ \\
7. Internal Health Control & $.634^{* *}$ \\
8. External Health Control & $.776^{* *}$ \\
9. Health Expectations & $.732^{* *}$ \\
10. Health Status &
\end{tabular}

Note.

**. Correlation is significant at the 0.01 level (2-tailed).

(.70-.94). Moreover, the paired samples t-test revealed no significant differences between the two testing points. These findings suggest that the test-retest reliability of the Greek version of the HOS is good.

\section{RELATIONSHIP TO GENDER AND AGE}

To determine whether gender and age would be associated with the scores on the HOS, independent samples t-test and ANOVA were conducted on the ten subscales of the Health Orientation Scale. Subjects were trichotomized into three groups on the age variable: young ( 25 years old or younger), middle (26-39 years old), and older (40 years old or older), as in the original validation of the scale.

Gender Main Effects. Males had higher scores than females on the "Motivation to Avoid Unhealthiness" and "Internal Health Control" subscales, and women had a higher score than men in the rest eight subscales. However, all these differences were not statistically significant.

Age Main Effects. Older participants (=>40 years old) reported more Health Image concerns than did middle age (26-39 years old) and younger individuals ( $\leqslant 25$ years old) $[\mathrm{F}(2,348)=7.04, p=0.001]$. In addition, it was found that older persons (=>40 years old) expressed higher motivation to Avoid unhealthiness than younger ( $\leqslant 25$ years old) and middle-aged (26-39 years old) individuals $[\mathrm{F}(2,348)=3.04$, $p=0.049$ ].

\section{DISCUSSION}

This study examined the factor structure and psychometric properties of the Health Orientation Scale in a Greek-speaking sample in Greece and Cyprus. This is a first step for the examination of the concept of Health Orientation in the Greek-speaking population.

The primary finding was that the Health Orientation Scale consists of ten subscales divided into three factors and its reliability and validity are adequate. Personal Health Consciousness, Health Esteem-Confidence, Motivation to Avoid Unhealthiness, Motivation for Healthiness, Health Expectations, and Health Status subscales all had high load- ings on Factor I. Factor II consisted of the subscales dealing with the Health Expectations and Health Status subscales. The third and final factor consisted of the subscales dealing with Internal Health Control and External Health Control. The structure of the HOS was entirely similar to that found in the original validation. ${ }^{6}$ An exception is noticed in the Personal Health Consciousness subscale. The initial validation presented high loading on Factor III (.41) and Factor I (.40). In this study it loaded on Factor I (.625). The factor loadings for the HOS items indicate that they are relatively good indicators of their respective factors.

As it is reported in the original validation, “...although these three clusters were found, it is important that researchers not arrive at the mistaken conclusion that the HOS subscales which loaded on each factor are assessing identical tendencies. Later results show, for example, that while some of these subscales relate to particular healthseeking behaviors, others do not". Moreover, "the loadings indicate that people who consider themselves healthy right now and who expect to continue feeling healthy in the future are the most motivated for good health, have higher health-esteem, and have higher levels of personal health consciousness." 6

Except of the subscale "External Health Control," the rest nine subscales of the Health Orientation Scale demonstrated good/excellent internal consistency. Cronbach's $\alpha$ for the "External Health Control" subscale was low (.46), but if item 38 was deleted, the value of Cronbach's $\alpha$ raised to an acceptable value (.65). We chose not to delete this item in order to retain the original 50 -items structure of the scale. However, we suggest that researchers examine if they want to eliminate/retain it from the total score of the subscale "External Health Control." In the original validation of the scale, reliability analyses confirmed that all ten subscales possessed acceptable levels of internal reliability, and Cronbach's $\alpha$ value for the "External Health Control” subscale was higher (.69).

There were many significant correlations between the ten subscales. The strongest correlation was recorded between the two health motivational subscales, with both motivational tendencies contributing to the personal health 
consciousness and health esteem-confidence. There was also a strong positive correlation between health esteemconfidence and motivation for healthiness with health expectations and health status. Similar results were found in the original validation 6 and indicate that people who derive a positive sense of esteem from their health and are motivated to keep themselves in great physical health evaluate their current health status as excellent and expect their health to remain excellent in the future. In addition, a strong positive correlation was found between health anxiety and health image concern, indicating that people who tend to be highly aware of the impression that their physical health makes on others tend to be anxious/nervous about their physical health-fitness.

Considering the above-mentioned low reliability of External Health Control, the rest nine subscales of the questionnaire present adequate test-retest reliability. The highest correlation index was recorded in Health Image Concern and Motivation to Avoid Unhealthiness subscales. These findings suggest that the test-retest reliability of the Greek version of the HOS is adequate. As was above mentioned, test-retest reliability was not examined in the original validation of the HOS.

Furthermore, the Health Orientation Scale demonstrated adequate construct (convergent and discriminant) validity. Specifically, the strongest correlations were the following:

- Health Anxiety (HA) was negatively correlated with body appreciation and positively with state and trait anxiety and total score of STAI.

- Health Esteem-Confidence (HEC) was correlated with body appreciation and life orientation and negatively correlated with state and trait anxiety and total score of STAI.

- Motivation to Avoid Unhealthiness (MAU) and Health Status (HS) were positively correlated with body appreciation and life orientation.

- Internal Health Control (IHC) was positively correlated with Internal Health Locus of Control

- External Health Control (EHC) was positively correlated with Chance Health Locus of Control, state and trait anxiety, and total score of STAI.

- Health Expectations (HE) was positively correlated with Life Orientation and body appreciation and negatively with state and trait anxiety and total score of STAI.

- Health Status (HS) was positively correlated with body appreciation and negatively with state and trait anxiety and total score of STAI.

It is noteworthy that in this study, construct validity was examined by computing correlations of Health Orientation with the above scales. In contrast, in the original validation, construct validity was examined by computing correlations of Health Orientation with several measures of health-seeking behaviors (e.g., exercise, smoking, etc.), and the analyses were conducted on females and males separately. These results suggest that the Greek version of the Health Orientation Scale has adequate construct (convergent and discriminant) validity. Similar results concerning the validity were reported in the original validation of the scale.

Males had higher scores than females on the "Motivation to Avoid Unhealthiness" and "Internal Health Control" subscales, and women had a higher score than men in the rest eight subscales. However, all these differences were not statistically significant. Similar results about the "Internal Health Control" subscale were found in the original validation of the scale.

Concerning age, older participants reported more Health Image Concerns than did middle age and younger individuals. In contrast, Snell et al. ${ }^{6}$ found that younger individuals reported more Health Image concerns than did middleaged individuals, who in turn indicated more health image concerns than did older people. In addition, it was found that older persons expressed higher motivation to Avoid unhealthiness than younger and middle-aged individuals. Different results were found in the original validation of the scale. Older persons expressed less Motivation for Healthiness (and not motivation to Avoid unhealthiness) relative to younger and middle-aged individuals. This indicates a change of older people to their health orientation, and it seems that they are highly motivated to avoid unhealthiness nowadays.

The advantages of this research include the examination of test-retest reliability and the examination of the construct validity utilizing many other related questionnaires. As for the limitations, it must be highlighted that younger people, women, and people with high educational levels were overrepresented in the sample due to the snowball sampling method used.

Despite these limitations, the Greek version of the HOS is reliable and valid for the investigation of health orientation and can be used for research and clinical purposes. Health psychologists could also use it in their everyday work to measure people's health-related personality tendencies.

Additional psychometric evaluation of the HOS in other samples and countries is needed to examine its cross-cultural structure and validity across various settings. Finally, future studies must examine the sociodemographic variables affecting health orientation in different cultural contexts.

\section{AUTHOR CONTRIBUTIONS}

Togas Constantinos had the idea for the research. He took the permission, distributed the questionnaire, performed the statistical analysis, wrote the article, and gave the final proof.

Parlalis Stavros conducted the pilot study of the questionnaire, distributed the questionnaire, made the proofreading, and gave the final proof.

\section{COMPETING INTERESTS}

There are no competing interests to report.

\section{FUNDING}

The authors have no funding to report. 


\section{ACKNOWLEDGMENTS}

Submitted: June 09, 2021 EST, Accepted: June 09, 2021 EST

We would like to thank the participants involved in this study for sharing their insights and time. 


\section{REFERENCES}

1. World Health Organization. Published 1946. http s://www.who.int/about/who-we-are/frequently-aske d-questions

2. Frech A. Healthy Behavior Trajectories between Adolescence and Young Adulthood. Advances in Life Course Research. 2012;17(2):59-68. doi:10.1016/j.alc r.2012.01.003

3. Dickinson A, MacKay D. Health habits and other characteristics of dietary supplement users: a review. Nutr J. 2014;13(1):14. doi:10.1186/1475-2891-13-14

4. Rimal RN, Flora JA, Schooler C. Achieving Improvements in overall health orientation: effects of campaign exposure, information seeking, and health media use. Communication Research. 1999;26(3):322-348. doi:10.1177/00936509902600300 $\underline{3}$

5. Marks D, Sykes C, McKinley J. Health psychology: overview and professional issues. In: Weiner I, ed. Handbook of Psychology. Vol 9. Health Psychology. John Wiley \& Sons, Inc; 2003.

6. Snell WE, Johnson G, Lloyd PJ, Hoover MW. The Health Orientation Scale: A measure of psychological tendencies associated with health. Eur J Pers. 1991;5:169-183. doi:10.1002/per.2410050208

7. Hampson S. Personality and Health.; 2017. doi:10.10 93/acrefore/9780190236557.013.121

8. Hill PL, Roberts BW. Personality and health: reviewing recent research and setting a directive for the future. In: Warner Schaie K, Willis S, eds. Handbook of the Psychology of Aging. 8th ed. Elsevier Inc; 2016:205-218. https://doi.org/10.1016/b978-0-1 2-411469-2.00011-x

9. Taylor MD, Whiteman MC, Fowkes GR, Lee AJ, Allerhand M, Deary IJ. Five-factor model personality traits and all-cause mortality in the Edinburgh artery study cohort. Psychosomatic Medicine. 2009;71(6):631-641. doi:10.1097/psy.0b013e3181a652 $\underline{98}$

10. Booth-Kewley S, Vickers RR. Associations between major domains of personality and health behavior. J Personality. 1994;62(3):281-298. doi:10.11 11/i.1467-6494.1994.tb00298.x

11. Wiebe DJ, Fortenberry KT. Mechanisms relating personality and health. In: Vollrath ME, ed. Handbook of Personality and Health. Wiley; 2006.
12. Goodwin RD, Stein MB. Peptic ulcer disease and neuroticism in the United States adult population. Psychother Psychosom. 2003;72(1):10-15. doi:10.1159/ $\underline{000067184}$

13. Raynor DA, Levine H. Associations between the five-factor model of personality and health behaviors among college students. Journal of American College Health. 2009;58(1):73-82. doi:10.3200/jach.58.1.73-82

14. Shoda Y, LeeTiernan S, Mischel W. Personality is a dynamic system: Emergence of stability and distinctiveness from intra- and interpersonal interactions. Pers Soc Psychol Rev. 2002;6(4):316-325. doi:10.1207/s15327957pspr0604 06

15. Antonovsky A. Health, Stress, and Coping. JosseyBass Publishers; 1979.

16. Antonovsky A. Unravelling the Mystery of Health: How People Manage Stress and Stay Well. Jossey-Bass Publishers; 1987.

17. Folkman S. The Oxford Handbook of Stress, Health and Coping. Oxford University Press; 2011.

18. Browning CR, Cagney KA, Iveniuk J. Neighborhood stressors and cardiovascular health: Crime and C-reactive protein in Dallas, USA. Social Science \& Medicine. 2012;75(7):1271-1279. doi:10.101 6/i.socscimed.2012.03.027

19. Daubenmier J, Lin J, Blackburn E, et al. Changes in stress, eating, and metabolic factors are related to changes in telomerase activity in a randomized mindfulness intervention pilot study. Psychoneuroendocrinology. 2012;37(7):917-928. doi:1 0.1016/i.psyneuen.2011.10.008

20. Seib C, Whiteside E, Lee K, et al. Stress, lifestyle, and quality of life in midlife and older Australian women: Results from the stress and the health of women study. Women's Health Issues.

2014;24(1):e43-e52. doi:10.1016/i.whi.2013.11.004

21. Rokach A. Health, illness, and the psychological factors affecting them. The Journal of Psychology. 2019;153(1):1-5. doi:10.1080/00223980.2018.1548202

22. Dutta M, Bodie G, Basu A. Health disparity and the racial divide among the nation's youth: Internet as a site for change? In: Everett A, ed. Learning Race and Ethnicity: Youth and Digital Media. The John D. and Catherine T. Mac Arthur Foundation Series on Digital Media and Learning. ; 2008. 
23. Dutta-Bergman MJ. Developing a profile of consumer intention to seek out additional information beyond a doctor: the role of communicative and motivation variables. Health Communication. 2005;17(1):1-16. doi:10.1207/s15327 027hc1701_1

24. Wallston KA, Wallston BS, DeVellis R. Development of the multidimensional health locus of control (MHLC) scales. Health Education Monographs. 1978;6(2):160-170. doi:10.1177/109019817800600107

25. Gureje O, Ustan TB, Simon GE. The syndrome of hypochondriasis: a cross-national study in primary care. Psychol Med. 1997;27:1001-1010. doi:10.1017/s0 $\underline{033291797005345}$

26. Bajcar B, Babiak J, Olchowska-Kotala A. Cyberchondria and its measurement. The Polish adaptation and psychometric properties of Cyberchondria Severity Scale CSS-PL. Polish Psychiatry. 2019;53(1):49-60. doi:10.12740/pp/81799

27. Hoque M, Alam MN, Nahid KA. Health consciousness and its effect on perceived knowledge, and belief in the purchase intent of liquid milk: Consumer insights from an emerging market. Foods. 2018;7(9):150. doi:10.3390/foods7090150

28. Hong H. Scale Development for Measuring Health Consciousness: Re-conceptualization. Published 2011. https://instituteforpr.org/health-consciousnes s/

29. McCabe S. Drink Sensibly? Alcohol consumption and its relationship with physical and mental health. Published online 2015.

30. Gordon ES, Gordish-Dressman HA, Devaney J, et al. Nondisease genetic testing: reporting of muscle SNPs shows effects on self-concept and health orientation scales. Eur J Hum Genet.

2005;13:1047-1054. doi:10.1038/sj.ejhg.5201449

31. Arif N, Qayyum S. Health orientation and healthpromoting behaviors in women. Journal of Postgraduate Medical Institute. 2019;33(1):34-40.

32. Knowles SR, Cook SI, Tribbick D. Relationship between health status, illness perceptions, coping strategies and psychological morbidity: A preliminary study with IBD stoma patients. Journal of Crohn's \& Colitis. 2013;27(10):e471-478. https://doi.org/10.101 6/j.crohns.2013.02.022
33. Wade JC. Traditional Masculinity and African American Men's Health-Related Attitudes and Behaviors. Am J Mens Health. 2009;3(2):165-172. do i: $10.1177 / 1557988308320180$

34. Van de Vijver F, Hambleton RK. Translating tests: Some practical guidelines. European Psychologist. 1996;1:89-99. doi:10.1027/1016-9040.1.2.89

35. Scheier MF, Carver CS, Bridges MW.

Distinguishing optimism from neuroticism (and trait anxiety, self-mastery, and self-esteem): A reevaluation of the life orientation test. Journal of Personality and Social Psychology. 1994;67:1063-1078. doi:10.1037/0022-3514.67.6.1063

36. Carver CS. Optimism, coping, and health: Assessment and implications of generalized outcome expectancies. Health Psychology. 1985;4:219-247. do i:10.1037/0278-6133.4.3.219

37. Carver CS, Scheier MF, Segerstrom SC. Optimism. Clinical Psychology Review. 2010;30:879-889. doi:10.1 016/i.cpr.2010.01.006

38. Lyrakos GN, Damigos D, Mavreas V, Kostopanagiotou G, Dimoliatis ID K. translation and validation study of the life orientation test revised in the Greek-speaking population of nurses among three hospitals in Athens and Ioannina. Soc Indic Res. 2009;95(1):129-142. doi:10.1007/s11205-009-9453-6

39. Avalos L, Tylka TL, Wood-Barcalow N. The Body Appreciation Scale: Development and psychometric evaluation. Body Image. 2005;2:285-297. doi:10.1016/ j.bodyim.2005.06.002

40. Alexias G, Togas C, Mellon R, R. Psychometric properties of the Greek version of the body appreciation scale. Hellenic Journal of Psychology. 2016;13(3):73-92.

41. Spielberger CD. State-Trait Anxiety Inventory. Consulting Psychologists Press; 1983.

42. Spielberger CD. State-Trait Anxiety Inventory: Bibliography. 2nd ed. Consulting Psychologists Press; 1989.

43. Fountoulakis, K., Papadopoulou, M., Kleanthous, S., Papadopoulou, A., Bizeli, V., Nimatoudis, I., Iacovides, A., \&Kaprinis, S. Reliability and psychometric properties of the Greek translation of the State-Trait Anxiety Inventory-Form Y: Preliminary data. Annals of General Psychiatry. 2006;5:2. 


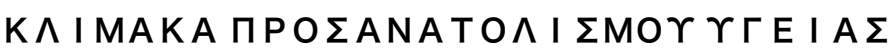

\begin{tabular}{|c|c|c|}
\hline \multicolumn{3}{|c|}{ 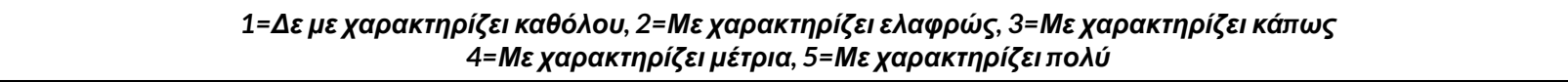 } \\
\hline 1 & 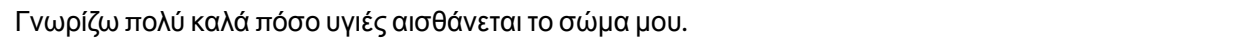 & 12345 \\
\hline 2 & 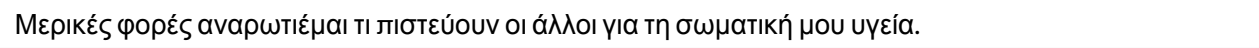 & 12345 \\
\hline 3 & 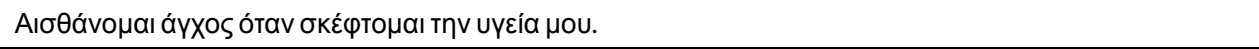 & 12345 \\
\hline 4 & 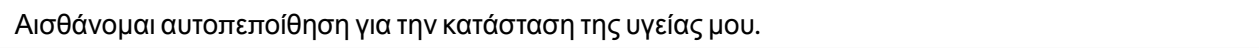 & 12345 \\
\hline 5 & 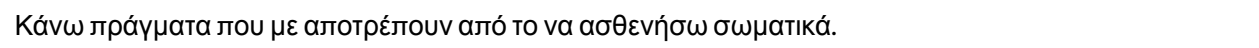 & 12345 \\
\hline 6 & 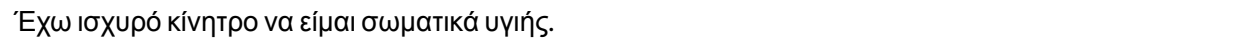 & 12345 \\
\hline 7 & 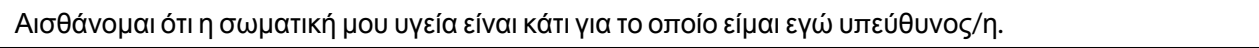 & 12345 \\
\hline 8 & 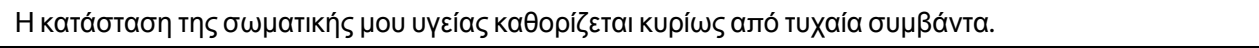 & 12345 \\
\hline 9 & 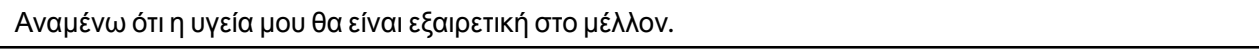 & 12345 \\
\hline 10 & 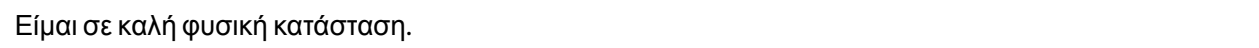 & 12345 \\
\hline 11 & 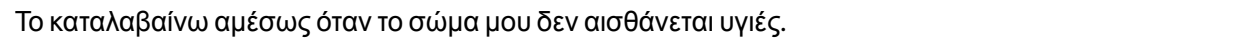 & 12345 \\
\hline 12 & 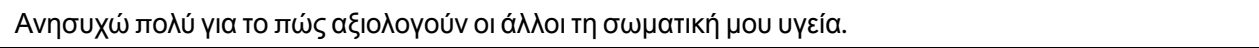 & 12345 \\
\hline 13 & 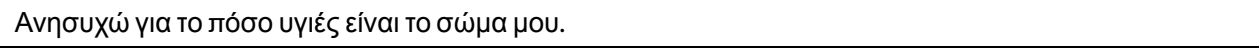 & 12345 \\
\hline 14 & 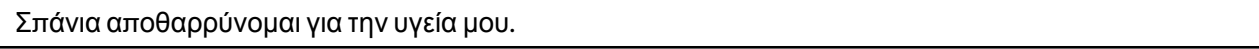 & 12345 \\
\hline 15 & 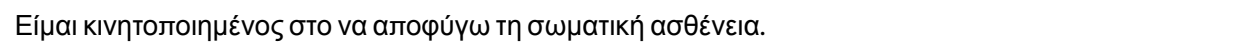 & 12345 \\
\hline 16 & 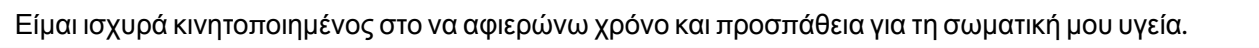 & 12345 \\
\hline 17 & 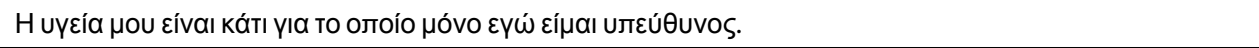 & 12345 \\
\hline 18 & 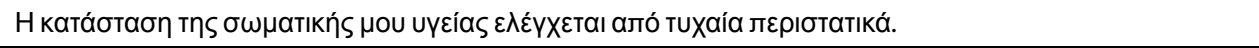 & 12345 \\
\hline 19 & 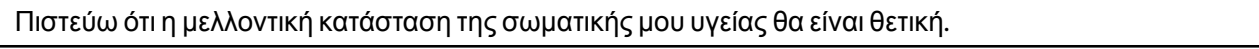 & 12345 \\
\hline 20 & 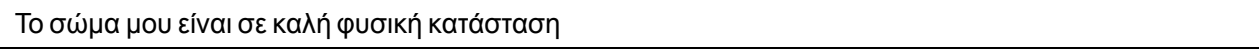 & 12345 \\
\hline 21 & 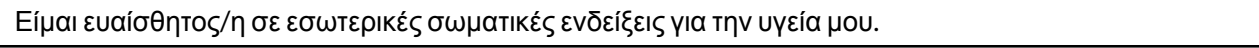 & 12345 \\
\hline 22 & 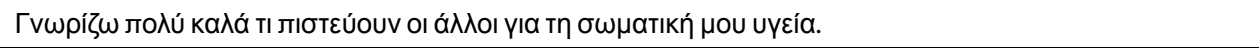 & 12345 \\
\hline 23 & 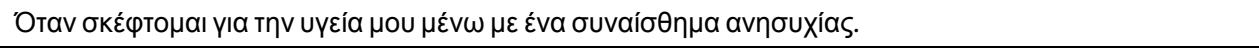 & 12345 \\
\hline 24 & 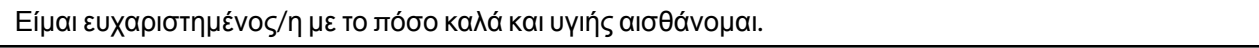 & 12345 \\
\hline 25 & 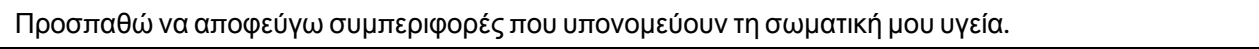 & 12345 \\
\hline 26 & 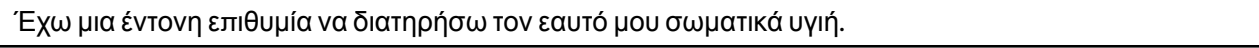 & 12345 \\
\hline 27 & 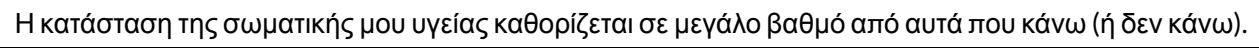 & 12345 \\
\hline 28 & 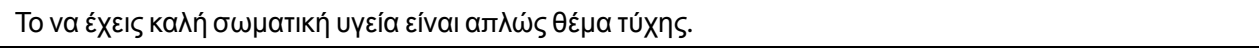 & 12345 \\
\hline 29 & 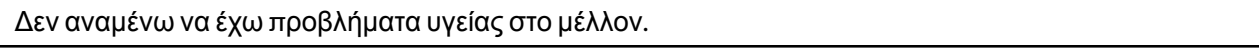 & 12345 \\
\hline 30 & 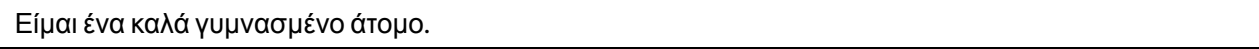 & 12345 \\
\hline 31 & 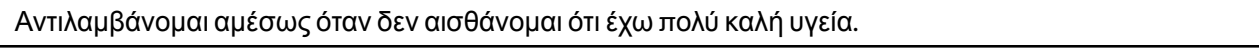 & 12345 \\
\hline 32 & 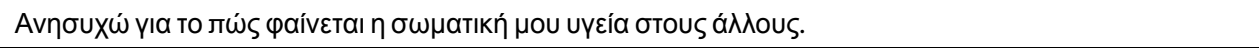 & 12345 \\
\hline 33 & 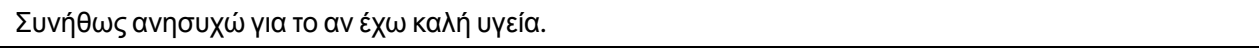 & 12345 \\
\hline 34 & 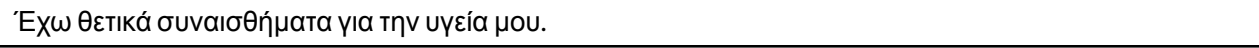 & 12345 \\
\hline 35 & 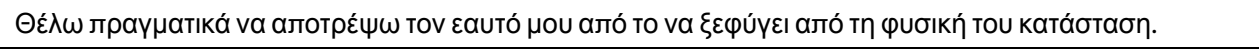 & 12345 \\
\hline 36 & 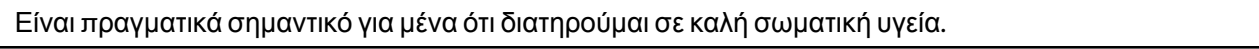 & 12345 \\
\hline 37 & 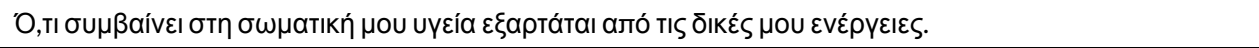 & 12345 \\
\hline 38 & 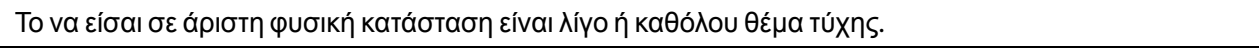 & 12345 \\
\hline 39 & 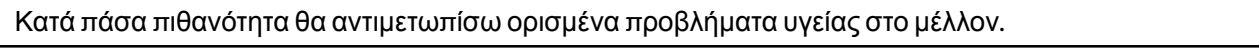 & 12345 \\
\hline 40 & 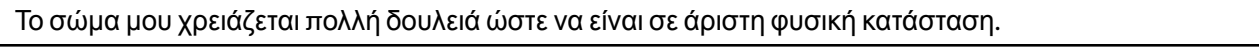 & 12345 \\
\hline 41 & 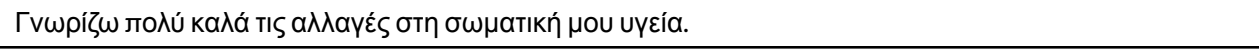 & 12345 \\
\hline 42 & 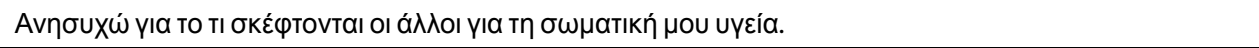 & 12345 \\
\hline 43 & 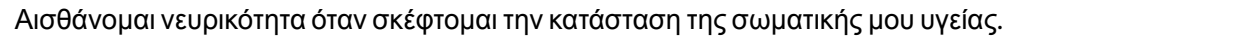 & 12345 \\
\hline
\end{tabular}




\begin{tabular}{|c|c|c|}
\hline 44 & 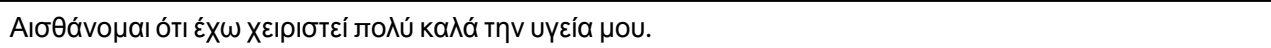 & 12345 \\
\hline 45 & 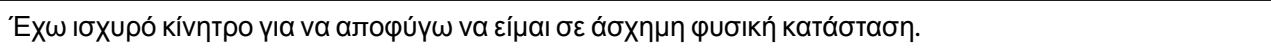 & 12345 \\
\hline 46 & 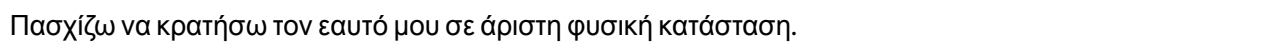 & 12345 \\
\hline 47 & 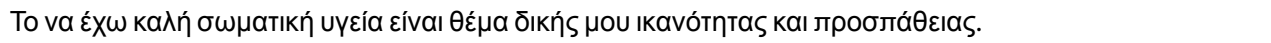 & 12345 \\
\hline 48 & 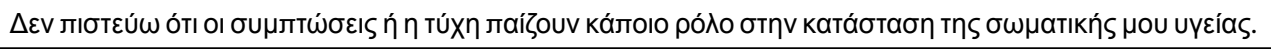 & 12345 \\
\hline 49 & 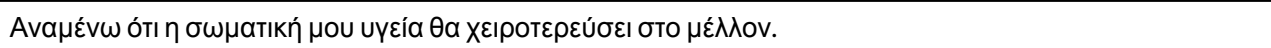 & 12345 \\
\hline 50 & 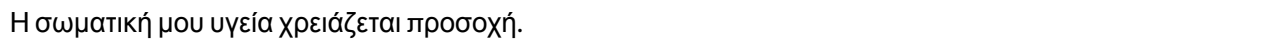 & 12345 \\
\hline
\end{tabular}

